\title{
Assessment of schistosomiasis and intestinal helminths following mass drug administration in the Centre and Plateau Central regions of Burkina Faso
}

\author{
Dramane ZONGO $^{1 *}$, Mohamed BAGAYAN ${ }^{1,2}$, Simon TIENDRÉBEOGO ${ }^{1}$, \\ François DRABO $^{3}$, Hamado OUEDRAOGO $^{3}$, Boubacar SAVADOGO ${ }^{1}$, \\ Issouf BAMBA ${ }^{4}$, Fanny YAGO-VIENNE ${ }^{4}$, Yaobi ZHANG $^{5}$ and Jean Noel PODA ${ }^{1}$ \\ ${ }^{1}$ Health Sciences Research Institute (IRSS), Ouagadougou, Burkina Faso. \\ ${ }^{2}$ University of Ouagadougou, Ouagadougou, Burkina Faso. \\ ${ }^{3}$ Unit for the Elimination of Schistosomiasis, Coordination of Neglected Tropical Diseases, Directorate for \\ Disease Control, Ministry of Health, Ouagadougou, Burkina Faso. \\ ${ }^{4}$ Helen Keller International, Ouagadougou, Burkina Faso. \\ ${ }^{5}$ Helen Keller International, Regional Office for Africa, Dakar, Senegal. \\ *Corresponding author; E-mail: dramanezongo@yahoo.fr, zdramane@gmail.com
}

\begin{abstract}
Schistosomiasis is the most important waterborne disease in Sub-Saharan Africa. Transmission is governed by the spatial distribution of specific freshwater snails that act as intermediate hosts and human water contact patterns. In developing countries, such as Burkina Faso it remains a serious health problem, which management face important gaps. The main of theses gaps is the lack of reliable information about prevalence. Then, this study has been undertaken in order to determine the prevalence of schistosomiasis in the Centre and Plateau Central regions in Burkina Faso. A cross-sectional descriptive study was conducted in the Plateau Central and Centre regions of Burkina Faso to assess the status of schistosomiasis and intestinal worms among school age children. 1,455 school-age children were selected to participate to the study. Results shows that prevalence of Schistosoma haematobium in the Plateau Central and Centre regions were $4 \%$ and $0.6 \%$ respectively, with an overall prevalence of $2.3 \%$ (95\% CI: $1.5 \%-3.1 \%$ ) in two regions. The following intestinal parasites were found in stools with various prevalence: Schistosoma mansoni $0.1 \%$ (95\% CI: $0 \%$ $0.3 \%$ ) and Ancylostoma duodenale $0.1 \%$ (95\% CI: $0 \%-0.2 \%$ ). The prevalence of urinary schistosomiasis in the Centre and Plateau Central regions had been greatly reduced from the previous level in the published data since the large-scale population treatment initiated in 2004. The study confirmed the success in controlling the disease by preventive chemotherapy. However, the progress toward its elimination requires that the implementation of a monitoring and evaluation system focused on sentinel sites, and aiming at quantifying the impact of treatment, be gradually coupled with a monitoring system to identify any outbreak of residual transmission.
\end{abstract}

(C) 2016 International Formulae Group. All rights reserved

Keywords: Schistosoma soil-transmitted helminths, mass drug administration, Burkina Faso.

\section{INTRODUCTION}

Economic development process typically generates health risks, starting from household to the community and then the risk takes on a global dimension (Mc Michael et al., 2003; Smith and Ezzati, 2005) through 
water resources management. The prevalence and incidence of diseases related to aquatic ecosystems are influenced by hydrological changes that occur during water resource use and management. Almost $90 \%$ of the global burden of disease due to schistosomiasis affects populations in sub-Saharan Africa. Some waterborne and vector borne diseases, relatively significant for the Sub-Region, are emerging as public health issues (IMCHI/1/CP8, 2008). The spread of schistosomiasis is related to the development of water sources and lack of hygiene in management of stools and urine (Ermould et al, 2003), and this remains a problem in developing countries, such as in Burkina Faso. To fight helminths, the Ministry of Health of Burkina Faso set up a national program against schistosomiasis in 2004. The goal of this national program is to reduce by $75 \%$ the prevalence of schistosomiasis according to the objectives of the World Health Assembly (WHA) resolution 54.19 (WHO, 2013). The control method chosen by the national program is based on annual campaigns of large-scale mass treatment with praziquantel (PZQ) nationwide, targeting school age children initially and then school age children plus at risk adults. At the same time, albendazole was also given simultaneously to control soil-transmitted helminthes. A mapping of schistosomiasis was achieved from 2004 to 2005 to identify areas of high prevalence. Following this, sentinel sites were selected for schistosomiasis monitoring and evaluation of the program. Sentinel sites are located in eleven regions of Burkina Faso, while no sentinel sites were established in the Centre and Plateau Central regions. Following a request made by the Kingdom of Morocco, a resolution on the elimination of schistosomiasis was approved in May 2012 by the World Health Assembly (WHA65.19). World Health Organization (WHO) is now considering the possibility of eliminating schistosomiasis as a public health problem and interrupting transmission.

Since the start of the national schistosomiasis program, Burkina Faso has been adopting a biennial treatment strategy for all endemic regions. Treatment in Centre and Plateau Central regions started in 2005 with 5 rounds of treatments had been delivered by 2013. In response to schistosomiasis elimination according to the WHA resolution 65.19 , a national re-assessment of schistosomiasis was conducted in sentinel sites across 11 regions. As there are no sentinel sites in the Centre and Plateau Central regions, a separate survey was conducted in these two regions to assess the endemic status in order to realign the treatment strategy to the WHO recommendations. In view of this, this study aimed to assess the status of schistosomiasis and intestinal helminths in the Centre and Plateau Central regions of Burkina Faso in connection with praziquantel distribution program done by the National Schistosomiasis Control Program (PNLSc) in order to support schistosomiasis management programs (treatment, monitoring and evaluation of parasite transmission process).

\section{Materials and Methods Study sites}

This study was conducted in the Centre and Plateau Central regions of Burkina Faso. theses regions are subject to Sudano-Sahelian climate characterized by irregular and insufficient rainfall, annual average ranging from 600 to $850 \mathrm{~mm}$, two main seasons (the dry season and the rainy season) and an average annual temperatures between $17{ }^{\circ} \mathrm{C}$ and $36{ }^{\circ} \mathrm{C}$. The districts selected in Plateau Central region are: Ziniaré, Zorgho, and Boussé. Two villages were selected in each district. These include Sawana and Bissiga (Ziniaré); Tuire and Zongou (Zorgho) and Sao and Golmidou (Boussé). The sites selected in the Centre region include the health districts of Bogodogo, Nongr Massoum, and SigNoghin. Two villages were selected in each district: Tanghin, Naaba zaana (Bogodogo), Sakoula, Roumtenga (Nongr-Massom), Kamboinsé, and Bassinko (Sig Nonghin): The choice of these villages was made on the basis of the availability of a water reservoir near dwellings and the availability of previous data 
on schistosomiasis. The main rivers crossing these regions are the Nakambé, Massili, Koulottoko, Nazinon, Bougoula-moudi, Bombore, and guibga rivers.

\section{Ethics, consent and permissions}

This study was part of the national Neglected Tropical Disease (NTD) control program and was approved by the ethics committee of the Ministry of Health of Burkina Faso. The survey was conducted by the national team through the Directorate for Disease Control. The collection of stool and urine specimens from children was approved by the various health districts and health Centre regions in the selected villages. The objectives of the survey were explained to the parents and children expected to participate to the survey to obtain their consent. Children who agreed to participate in the study were identified and codified. A number was assigned to each participant and the same number was labeled on their collection pots to maintain the confidentiality of results. No personal data can be revealed.

\section{Study population}

The day before the survey, a team consisting of the nurse and the community health worker asked all families to send their children aged 5-15 years. The following day, the children were recruited in the public square in every village where they were brought together. The study population consists of both male and female school-age children aged 5-15 years. The first children to arrive at the sampling site were recruited for the survey following an interview with their parents. The only criterion used to select participants was the age criterion.

The sample size was calculated as 196 for each district, using an estimated prevalence of $15 \%$, confidence level $95 \%$, and $5 \%$ precision.

$\mathrm{N}=\mathrm{N}:$ Sample size : Confidence level= 1,96; P : Estimated prevalence $=15 \%$

: Degree of precision $=0,05 . \mathrm{N}=($ $\mathrm{N}=\mathbf{1 9 6}$

The minimum size of the expected total sample was 1,176 children in six districts in two regions. At the end of the collection, 1,455 children were surveyed. Each of the sampled children received two collection pots: one for the stool and one for urine.

Samples were taken between $8 \mathrm{am}$ and 10am. Some children were accompanied by a family member to properly take their sample. After collection, the samples were carried to laboratories in each health district for analysis. The Kato-Katz method was applied to the stool and the method of filtration of urine was used for the urine.

\section{Parasitological examination Stool samples}

The Kato-Katz method was used for the detection of Schistosoma mansoni, hookworm, Ascaris lumbricoides and Trichuris trichiura eggs in feces (Katz et al, 1972). The sampled amount is deposited on a slide and covered with a cellophane membrane previously soaked in malachite green solution (5\%) for 24 hours. Reading was made under a light microscope at 10X40 magnification. Conversion of egg counts/slide into eggs per gram of feces (epg) was done by multiplication by 40 , as under operational circumstances (presuming an average weight per sample of $25 \mathrm{mg}$ ). The mean egg load was calculated as the geometric mean of positive individual epg of faeces.

\section{Urine samples}

The method of filtration of urine was used (Plouvier et al, 1975) for the detection of $S$. haematobium eggs in the urine. It consists of filtering $10 \mathrm{ml}$ of urine with a nytrel filter contained in a filter holder. The filter is then placed on a slide and stained with Lugol and subsequently covered with a cover glass; and observed with a light microscope. The intensity of infection was estimated as number of eggs $/ 10 \mathrm{ml}$ urine.

\section{Statistical Analysis}

The collected data were entered using the SPSS software. They were then analyzed using the statistical package SPSS 20.0 (IBM). Comparisons were made using Pearson's Chi-squared tests for prevalence. 
For this purpose, a p-value of $\leq 0.05$ was considered statistically significant. The $95 \%$ confidence interval of prevalence was determined using descriptive statistics with
SPSS 20.0 software. The arithmetic mean of all examined children with the standard error of the mean was used to calculate the intensity of infection.

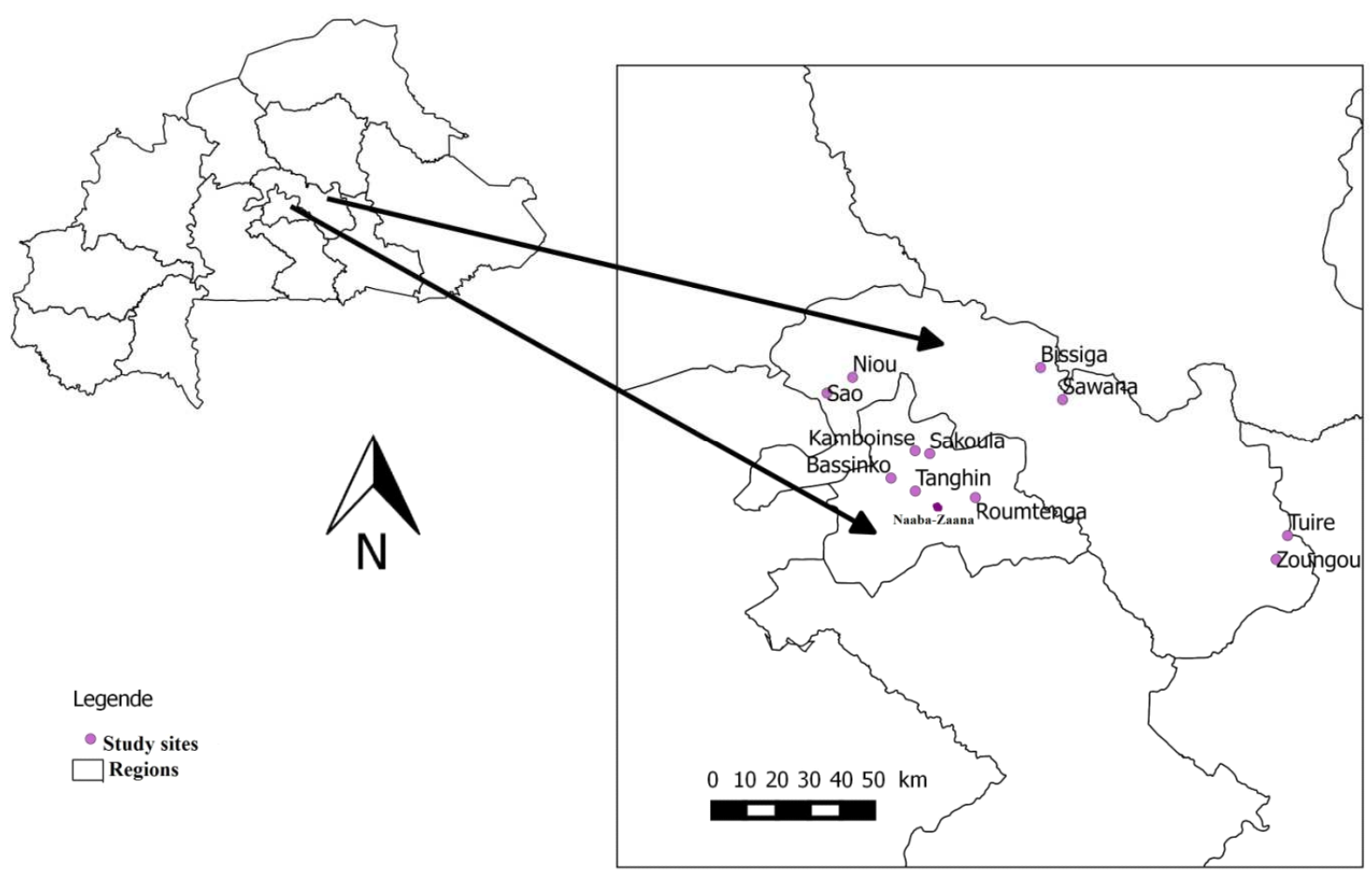

Figure1: Location of the villages selected in the Centre and Plateau Central regions

\section{RESULTS}

The results are summarized in Tables 1 and 2. A total of 12 villages in the two regions were selected for parasitological examination. 1,455 school-age children participated in this study. The mean age was $9.5 \pm 0.065$ years.

The results of urinary schistosomiasis by sex, age and status of participants are indicated in Table 1. The overall prevalence of $S$. haematobium is $2.3 \%$ (95\% CI: $1.5 \%$ $3.1 \%)$. Among 12 villages surveyed, the prevalence of S. haematobium varied from $0 \%$ - 14\%. No positive cases were found in 6 villages. The prevalence of urinary schistosomiasis was $14 \%$ in Zoungou, $7.1 \%$ in
Sawana, $2.5 \%$ in Bassinko, $2 \%$ in Sao and $0.8 \%$ in Tanghin and Niou, Golmidou. The prevalence of $2.3 \%$ (95\% CI: 1.6-3.2) for 33 children infected by $S$. haematobium, an arithmetic mean intensity was 3.49 (95\% CI: $0.38 ; 6.61)$.

The overall prevalence of $S$. mansoni was $0.1 \%$ (95\% CI: $0 \%-0.2 \%)$. S. mansoni eggs were identified only in the villages of Niou and Sao with respective prevalence of $0.8 \%$ and $0.7 \%$. Among geohelminths, only one case of Ancylostoma duodenale was identified in Zoungou village in this study with the prevalence of $0.1 \%(95 \% \mathrm{CI}: 0 \%-$ $0.2 \%$ ). 
Table 1: Results of schistosomiasis and soil-transmitted helminths by gender, status and age

\begin{tabular}{llccccc} 
& \multirow{2}{*}{$\mathbf{N}$} & \multicolumn{2}{c}{ S. haematobium } & \multicolumn{2}{c}{ S. mansoni } \\
\cline { 3 - 6 } & & & Prev. & MI & Prev. & MI \\
\hline Sex & Male & 729 & $3.2(2.1-4.7)$ & $6.41(0.23-12.59)$ & $0.3(0.1-1.1)$ & $2.79(0-8.15)$ \\
& Female & 726 & $1.4(0.7-2.5)$ & $0.56(0.02-1.10)$ & $0(0-0)$ & - \\
\hline Status & In-school & 1203 & $1.6(0.1-2.5)$ & $3.29(0-6.93)$ & $0.2(0-0.7)$ & $1.69(0-4.94)$ \\
& Out-of-school & 252 & $5.6(3.3-9.2)$ & $4.47(0-9.08)$ & $0(0-0)$ & - \\
\hline Age & $5-8$ & 611 & $2.1(1.2-3.6)$ & $1.94(0-3.92)$ & $0.2(0-1.2)$ & $0.07(0-0.22)$ \\
group & $9-11$ & 491 & $2.2(1.2-4.0)$ & $7.15(0-16.01)$ & $0(0-0)$ & - \\
(years) & $12-15$ & 353 & $2.5(1.3-4.8)$ & $1.09(0.27-1.91)$ & $0.3(0-2)$ & $5.64(0-16.70)$ \\
\hline
\end{tabular}

N: number of children examined, Prev.: prevalence parasite and by $95 \%$ CI, MI: mean Intensity of the infection (eggs/10 ml of urine for S. haematobium and epg for S. mansoni ) and $95 \%$ CI

Table 2. Results of schistosomiasis and soil-transmitted helminths by region and district

\begin{tabular}{|c|c|c|c|c|c|c|}
\hline Region & Districts & $\begin{array}{l}\text { No of } \\
\text { children } \\
\text { examined }\end{array}$ & $\begin{array}{l}\text { Prevalence of } S . \\
\text { haematobium } \\
(\%)(95 \% \mathrm{CI})\end{array}$ & $\begin{array}{l}\text { Mean intensity of S. haematobium infection (eggs/10 } \\
\text { ml of urine) }(95 \% \mathrm{CI})\end{array}$ & $\begin{array}{l}\text { Prevalence of } S . \\
\text { mansoni }(\%) \\
(95 \% \mathrm{CI})\end{array}$ & $\begin{array}{l}\text { Mean intensity of } S \\
\text { mansoni infection } \\
\text { (epg) }(95 \% \mathrm{CI})\end{array}$ \\
\hline \multirow[t]{4}{*}{ Centre } & Bogodogo & 232 & $0.4(0.1-3)$ & $0.01(0-0.02)$ & 0 & - \\
\hline & Nongr-Massoum & 251 & 0 & - & 0 & - \\
\hline & Sig-Nonghin & 241 & $1.2(0.4-3.8)$ & $5.16(0-12.96)$ & 0 & - \\
\hline & Sub total & 724 & $0.6(0.2-1.5)$ & $1.72(0-4.32)$ & 0 & - \\
\hline \multirow{4}{*}{$\begin{array}{l}\text { Plateau } \\
\text { central }\end{array}$} & Ziniaré & 222 & $3.6(1.8-7.0)$ & $12.87(0-31.18)$ & 0 & - \\
\hline & Zorgho & 235 & $7.2(4.5-11.3)$ & $3.84(1.34-6.34)$ & 0 & - \\
\hline & Boussé & 274 & $1.5(0.5-3.8)$ & $0.28(0-0.60)$ & $0.7(0.2-2.9)$ & $7.44(0-21.68)$ \\
\hline & Sub total & 731 & $4(2.8-5.7)$ & $5.25(0-10.88)$ & $0.3(0.1-1.1)$ & $2.79(0-8.13)$ \\
\hline
\end{tabular}




\section{DISCUSSION}

In this study two species of schistosomes infecting human were detected: S. haematobium $(2.3 \%)$ and S. mansoni $(0.1 \%)$.

S. haematobium, unlike S. mansoni, was found throughout Burkina Faso (Poda and Traoré, 2000). In Ziniaré, Garba et al. (1999) found in five villages around the dam of Ziga that prevalence of $S$. haematobium ranged from $26 \%$ to $76 \%$ (Garba et al., 1999). Specifically in Sawana, these authors found a prevalence of urinary schistosomiasis of $43 \%$ (Garba et al., 1999), while the prevalence in the same village was $7.1 \%$ in our study in 2013. In the Centre region the prevalence of $S$. haematobium ranged from 10 to $88 \%$ in 1978 (Poda and Traoré, 2000). In this study, the prevalence of $S$. haematobium was $0.6 \%(95 \%$ CI: $0.2 \%-1.5 \%$ ) in the Centre region. In general, there was a decrease in prevalence in both regions. This is attributable to mass treatment with praziquantel. Same decreasing pattern in the prevalence of schistosomiasis and the intensity of infection was noticed in 2007 following a large-scale treatment with praziquantel in Burkina Faso (Koukounari et al., 2007; Touré et al., 2008). The efficacy of praziquantel in schistosomiasis control was shown in numerous studies (Garba et al., 2004; Barkia et al., 2011; Emukah et al., 2012). When comparing the results by region, the Plateau Central recorded the higher prevalence of urinary schistosomiasis ( $\mathrm{p}<$ 0.001 ). This is thought to be related to the impacts of urbanization. In fact, unlike the Centre region, river impoundment is more often and reservoirs are numerous in the Plateau Central. This increases the risk of contamination of water with schistosome eggs (Poda, 2007). Furthermore, studies have also shown that people close to water reservoirs are usually the most affected (Hamburger et al., 2004; Ould et al., 2011).

The results showed that boys were more infected than girls $(\mathrm{p}=0.023)$. This may be attributed to the continued presence of boys in aquatic environments for various reasons such as fishing and swimming activities.
Unlike boys, girls are less in contact with aquatic environments. They attend such environments early in the morning for reasons of social obligations, such as domestic chores, and at that time the emission of cercariae by infected snails is low (Poda et Traoré, 2000; Adoubryn et al., 2006; Zongo et al., 2012). This may be also due to decency that may prevent girls from undressing and swimming in the presence of boys.

When considering the prevalence by age, the highest prevalence was in the age group $12-15$ years. This may be due to the fact that at this age parents have little control over their children and moreover the latter are very mobile. According to school status, outof-school children were more infected than children in school ( $\mathrm{p}<0.001)$. This difference in prevalence may be due to the fact that outof-school children are involved in market gardening and fishing activities and have more free time than school children to go swimming in water reservoirs (ponds, rivers, dams and lakes) (Cecchi, 1999). In addition, they are very-hard-to reach in large-scale treatment campaigns against schistosomiasis.

During this study, two cases of intestinal schistosomiasis were found in the Plateau Central region with a prevalence of $0.1 \%$. The presence of $S$. mansoni in Boussé district could be explained by the presence of holidaymakers in the area because $S$. mansoni is normally found in the west part of Burkina Faso. Two infected children were in school, and moreover, sampling was made during the school holidays. That mean the two children imported this parasite from and other area. We make this assumption because such schistosome species is rarely found in the Sahelian and Northern Sudanese climate in Burkina Faso (Poda et Traoré, 2000). The same observation was made in numerous studies in the Centre and Plateau Central regions (Garba et al., 1999; Poda, 2007; Traoré et al., 1990; Dianou et al., 2004; Zongo et al., 2009; Bagayan, 2012).

In this study, a single positive case of hookworm (A. duodenale) infection was detected. The other two soil-transmitted 
helminthes (A. lumbricoides and T. trichiura) were not detected. This may be due to the effects of mass treatment with albendazole. In Burkina Faso, children had been treated with albendazole through mass treatment against lymphatic filariasis and against schistosomiasis. In Centre and Plateau Central, mass drug administration with albendazole and ivermetin for lymphatic filariasis elimination started in 2005. A minimum of five rounds of treatment had been conducted targeting population of $\geq 5$ years old. Through schistosomiasis MDA, five rounds of albendazole treatment had been given to school age children. Significant decrease in the prevalence of STHs was reported after mass treatment campaigns in country like Cameroon (Nkengazong et al., 2010; Karunaithas et al., 2012).

In addition, children in the Plateau Central region were more infected than those of the Centre region $(p=0.026)$. Centre region is heavily urbanization compared to the Plateau Central region. Improving the living conditions of people significantly contributes to fighting against helminths. The availability of running water and boreholes contributes to preventing contact with the aquatic environment and reducing the risk of contamination with $S$. haematobium.

\section{Conclusion}

This study showed that the prevalence of urinary schistosomiasis in the Centre and Plateau Central regions had been greatly reduced from the previous level in the published data since the large-scale population treatment was initiated in 2004. The study confirmed the success in controlling the disease by preventive chemotherapy. The data showed that the elimination of schistosomiasis is achievable in some geographical and epidemiological areas in Burkina Faso. However, the progress toward its elimination requires that the implementation of a monitoring and evaluation system focused on sentinel sites, and aiming at quantifying the impact of treatment, gradually coupled with a monitoring system to identify any outbreak of residual transmission especially with dams and irrigation schemes. This could be supported by an active component (epidemiological studies) and a passive component (case reporting / routine monitoring by the health districts' health system). Malacology can also provide useful information for site characterization and for the identification of the most appropriate control tools.

\section{COMPETING INTERESTS}

The authors declare that they have no competing interests.

\section{AUTHORS' CONTRIBUTIONS}

DZ, FD, HO conceived and designed the experiments; DZ, MB, HO, FD collected the data and performed the experiments; ST, DZ analysed the data; BS contributed materials/analysis tools; DZ, MB, YZ, IB, FYV, JNP wrote the paper.

\section{ACKNOWLEDGEMENTS}

This study was made possible with funding from the United States Agency for International Development (USAID) through a grant to Helen Keller International under Cooperative Agreement with the End in Africa Project managed by Family Health International 360. The contents are the responsibility of the authors and do not necessarily reflect the views of USAID or the United States Government. We are indebted to the residents of the districts selected: Ziniaré, Zorgho, Boussé, Bogodogo, Nongr Massoum, and Sig-Noghin for their participation in this study.

\section{REFERENCES}

Adoubryn KD, Ouhon J, Yapo CG, Assoumou EY, Ago KM, Assoumou A. 2006. Epidemiological profile of the schistosomiasis in school children in the Agneby Region (south-east of Coted'Ivoire). Bull Soc Pathol Exot., 99(1): 28-31.

Bagayan M. 2012. Schistosomiase en milieu peri-urbain : cas du quartier Yamtenga 
de la ville de ouagadougou (Burkina Faso). Univ Ouaga Mem DEA: 52.

Barkia H, Barkia A, Nhammi H, Belghyti D. 2011. Schistosomiasis in Morocco: from discovery to after elimination. East Mediterr Health J, 17(3): 250256.

Cecchi P. 1999. Schistosomiases et populations à risques dans les petits barrages. In L'Eau en Partage, Cecchi $\mathrm{P}$ (ed). IRD.

Dianou D, Poda JN, Savadogo L, Sorgho H, Wango S, Sondo B. 2004. Parasitoses intestinales dans la zone du complexe hydroagricole du Sourou au Burkina Faso. VertigO, 5.

Emukah E, Gutman J, Eguagie J, Miri ES, Yinkore P, Okocha N, Jibunor V, Nebe O, Nwoye AI, Richards FO. 2012. Urine heme dipsticks are useful in monitoring the impact of praziquantel treatment on Schistosoma haematobium in sentinel communities of Delta State, Nigeria. Acta Trop, 122(1): 126-131.

Garba A, Campagne G, Poda JN, Parent G, Kambire R, Chippaux JP. 1999. Schistosomiasis in the region of Ziga (Burkina Faso) before the construction of a dam. Bull Soc Pathol Exot, 92(3): 195-197.

Garba A, Campagne G, Tassie JM, Barkire A, Vera C, Sellin B, Chippaux JP. 2004. Long-term impact of a mass treatment by praziquantel on morbidity due to Schistosoma haematobium in two hyperendemic villages of Niger. Bull Soc Pathol Exot, 97(1): 7-11.

Hamburger J, Hoffman O, Kariuki HC, Muchiri EM, Ouma JH, Koech DK, Sturrock RF, King CH. 2004. Largescale, polymerase chain reaction-based surveillance of Schistosoma haematobium DNA in snails from transmission sites in coastal Kenya: a new tool for studying the dynamics of snail infection. Am J Trop Med Hyg, 71(6): 765-773.
Karunaithas R, Murugananthan A, Kannathasan S. 2012. Prevalence and associated factors of soil transmitted helminthes infestation among preschool children of Vadamaradchi Educational Zone. Ving Journal of Science, 10(1): 25-34.

Katz N, Chaves A, Pellegrino J. 1972. A simple device for quantitative stool thick-smear technique in Schistosomiasis mansoni. Rev Inst Med Trop Sao Paulo, 14(6): 397-400.

Koukounari A, Gabrielli AF, Toure S, Bosque-Oliva E, Zhang Y, Sellin B, Donnelly CA, Fenwick A, Webster JP. 2007. Schistosoma haematobium infection and morbidity before and after large-scale administration of praziquantel in Burkina Faso. J Infect Dis, 196(5): 659-669.

Nkengazong L, Njiokou F, Wanji S, Teukeng F, Enyong P, Asonganyi T. 2010. Prevalence of soil transmitted helminths and impact of Albendazole on parasitic indices in Kotto Barombi and Marumba II villages (South-West Cameroon). Afr J Environ Sci Technol, 4(3): 115-121.

Ould Ahmed Salem CB, Alassane MT. 2011. Prevalence and parasite load of urinary schistosomiasis in schoolchildren in the Wilaya of Gorgol in Mauritania. Med Trop (Mars), 71(3): 261-263.

Plouvier S, Leroy JC, Colette J. 1975. Présentation de deux techniques simples utilisables en enquête épidémiologique de bilharziose urinaire : la filtration des urines et des bandelettes réactives. In: XVè conf Tech OCCGE 1975.

Poda JN. 2007. Les maladies liées à l'eau dans le bassin de la Volta : état des lieux et perspectives. In: Volta Basin Focal Project Report No 4. edn. Montpellier: IRD.

Poda JN, Traoré A. 2000. Situation des schistosomoses au Burkina Faso. In: La lutte contre les schistosomoses en Afrique de l'Ouest. edn. Edited by 
Chippaux JP. Paris: Colloques et Séminaires: 177-195.

Smith KR, Ezzati M. 2005. How environmental risks change with development: the epidemiologic and environmental risk transitions revisited. Annual Review of Environment and Resources, 30: 291-333.

Traore LK, Ouedraogo LH, Pietra V, Nacoulma I, Nebie B, et al. 1990. Prévalence de l'infection à Schistosoma haematobium et relations bilharziose hématurie dans deux villages du Burkina Faso. Médecine d'Afrique Noire, 37(3): 100-107.

WHO. 2013. Schistosomiasis: number of people treated in 2011. Weekly Epidemiological Record, 88(8): 81-88.
Zongo D, Kabré BG, Dianou D, Sawadogo B, Poda JN. 2009. Importance of malacological factors in the transmission of Schistosoma haematobium in two dams in the province of Oubritenga (Burkina Faso). Res J Environ Sci, 3(1): 127-133.

Zongo D, Kabre BG, Dayeri D, Savadogo B, Poda JN. 2012. Comparative study of schistosomiasis transmission (urinary and intestinal forms) at 10 sites in Burkina Faso (in sub-Saharan Africa). Med Sante Trop, 22(3): 323-329. 